\title{
Evolution the Correlation Between the Severity of Cytomegalovirus Infection among Aborted Women with Vitamin D and Oxidative Stress Biomarkers
}

\author{
Batool A. Hussein*1, Khalid M. Dakhel ${ }^{* 2}$, Raid M. H. Al-Salih*3 \\ \{batoolhussein100@gmail.com ${ }^{1}$ \} \\ Ministery of health - AL-Shatraa General Hospital ${ }^{1}$ \\ Southern Technical University - Nassiriah Technical Institute - Community Health \\ Department $^{2}$ \\ University of Thi-Qar - College of Science- Department of Chemistry ${ }^{3}$
}

\begin{abstract}
The most common complication of early pregnancy is abortion. Embryo-fatal infections have been documented to cause less than $4 \%$ of spontaneous abortions (SAs). Viruses, notably cytomegalovirus, appear to be the most frequently involved pathogens. The study is a case-control study conducted in Bint Al-Huda Teaching Hospital in the period between October 2020 to March 2021. One hundred subjects enrolled in this study and divided into (25) aborted $\mathrm{CMV}^{+}$women, (25) aborted $\mathrm{CMV}^{-}$women, (25) non- aborted $\mathrm{CMV}^{+}$women as patients' groups, and (25) non- aborted women with cytomegalovirus seronegative test as a control group. This study was designed to assess the correlation between the severity of CMV infection among aborted women with VD levels and oxidative stress biomarkers (Malondialdehyde, Ceruloplasmin, and transferrin). Anticytomegalovirus antibody was positively correlated with vitamin D, MDA, and ceruloplasmin and negatively correlated with transferrin as an oxidative stress biomarker.
\end{abstract}

Keywords: Aboration, Cytomegalovirus, vitamin D, Oxidative stress

\section{Introduction}

Expulsion or evacuation of the embryo or foetus weighing less than $500 \mathrm{~g}$, which is comparable to around 20-22 weeks of gestation, is classified as miscarriage or spontaneous abortion. It is the most common early pregnancy problem [1]. 6-15 percent of all clinically confirmed pregnancies end in spontaneous abortion, according to estimates [2].

Genetic variables, anatomic factors, autoimmune illnesses, endocrine dysfunction, thrombophilia, lifestyle issues, and maternal infections all have a role in spontaneous abortion. However, in up to $50 \%$ of instances, the underlying cause remains unknown [3]. Embryo-fatal infections have been documented to cause less than $4 \%$ of spontaneous abortions (SAs). The creation of harmful metabolic by-products, as well as lethal or placental infection, are all conceivable mechanisms [4]. Viruses appear to be the most commonly involved pathogens, and CMV is a common virus that can reach the placenta by viremia, which can occur after both primary and recurrent infection, or via an ascending route from the cervix, which is the most common route [5]. 
After viral infections, reactive species are frequently generated. Reactive species are protected by antioxidant defences, which include both enzymatic and non-enzymatic components. Oxidative stress is defined as an imbalance in the creation of reactive species and the body's incapacity to detoxify these reactive species [6].

Vitamin D is a secosteroid hormone that helps maintain mineral balance and bone metabolism [7]. Vitamin D regulates the immune system in addition to its physiological role [8]. Low vitamin D levels during pregnancy may increase the risk of obstetrical problems [9]. A substantial percentage of RSA patients are said to be vitamin D deficient[10], and low vitamin $\mathrm{D}$ levels have been linked to an increased risk of miscarriage in the first trimester [11].

\section{Materials and Methods}

\subsection{Sample collection}

25 aborted women with CMV seropositive (A), 25 aborted women with CMV seronegative (B), and 25 non-aborted women with CMV seropositive (C) with an age range from (16-43) years were selected from those attending the Teaching Hospital of Bint Al-Huda at Thi-Qar province during the time between October 2020 and March 2021 were included in this study as patient groups. Another group of 25 healthy individuals (D) with an age range from (16-43 years) was included in this study as a control group.

\subsection{Exclusion Criteria}

Women with diabetes and cardiovascular illnesses, could be a good cause of abortion however, this has been excluded from this study. A 3-5 ml from each subject, as peripheral blood was collected by vein puncture. The collected samples were placed in a gel vacuum tube and allowed to clot at room temperature, and then the samples were centrifuged at 3600 rounds per minute (min) (RPM) for $10 \mathrm{~min}$ for serum separation. The collected sera were transferred to the different tubes and frozen at $-20{ }^{\circ} \mathrm{C}$ to be analysed later unless used immediately. Homolysis samples were discarded.

\subsection{Determination of Anti-Cytomegalovirus IgG and IgM Antibodies}

Bioactive Diagnostical used enzyme-linked immunosorbent test (ELISA) kits to measure CMV IgG and IgM. (Germany).

\subsection{Determination of Total Vitamin D}

Monobind Inc's enzyme-linked immunosorbent assay (ELISA) kit was used to detect total vitamin D. (USA).

\subsection{Determination of Malondialdehyde}

Sunlong used an enzyme-linked immunosorbent test (ELISA) kit to measure malondialdehyde (MDA) (China). 


\subsection{Determination of Ceruloplasmin}

Ceruloplasmin $(\mathrm{Cp})$ was tested by a biochemical method based on the $\mathrm{Cp}$-catalysed oxidation of colourless paraphenylenediamine (PPD) to blue-violet oxidize form.

\subsection{Determination of Transferrin}

Transferrin was measured by measuring both iron concentration and total iron-binding capacity (TIBC) and using the following formula

$$
T F\left(\frac{g}{l}\right)=T I B C(\mu g / L) X 0.007
$$

\subsection{Statistical Analysis}

Version 22 of the Statistical Package for Social Sciences (SPSS) was used. The correlation between continuous variables was determined using Pearson correlation coefficient analysis. $\mathrm{P}$-values of less than or equal to 0.05 are deemed significant $(\mathrm{p}<0.05)$.

\section{Results}

Table 1 shows the correlation between IgG titer and VD3 in all study groups. There was a positive non-significant Pearson correlation amongst IgG titer and VD in the aborted group with $\mathrm{CMV}$, non-aborted with CMV and control groups, and a negative non-significant correlation between IgG titer and VD in an aborted group with non-CMV.

Table 1. Correlation between $\operatorname{IgG}$ titer and total VD in all study groups.

\begin{tabular}{|c|c|c|c|c|c|c|c|c|c|}
\hline \multirow{3}{*}{$\begin{array}{l}\text { Study } \\
\text { Items }\end{array}$} & \multirow{3}{*}{$\begin{array}{l}\text { Statistic } \\
\text { Relation }\end{array}$} & \multicolumn{8}{|c|}{ Statistics } \\
\hline & & \multicolumn{2}{|c|}{ A } & \multicolumn{2}{|c|}{ B } & \multicolumn{2}{|c|}{$\mathrm{C}$} & \multicolumn{2}{|c|}{ D } \\
\hline & & IgG & Sig & IgG & Sig & IgG & Sig & IgG & Sig \\
\hline VD3 & $\begin{array}{c}\text { Pearson } \\
\text { correlation }\end{array}$ & .148 & .47 & $-.078-$ & .71 & .113 & .59 & .154 & .46 \\
\hline & No. & \multicolumn{2}{|c|}{25} & \multicolumn{2}{|c|}{25} & \multicolumn{2}{|c|}{25} & \multicolumn{2}{|c|}{25} \\
\hline
\end{tabular}

Table 2 shows the correlation between IgG and MDA levels in all study groups. Positive nonsignificant correlation between IgG titer and serum MDA in aborted with CMV and control groups. Table 2 also shows a negative correlation between IgG titer and serum MDA in aborted with non CMV and non-aborted with CMV groups.

Table 2. Correlation between cytomegalovirus IgG titer and serum MDA in all study groups. 


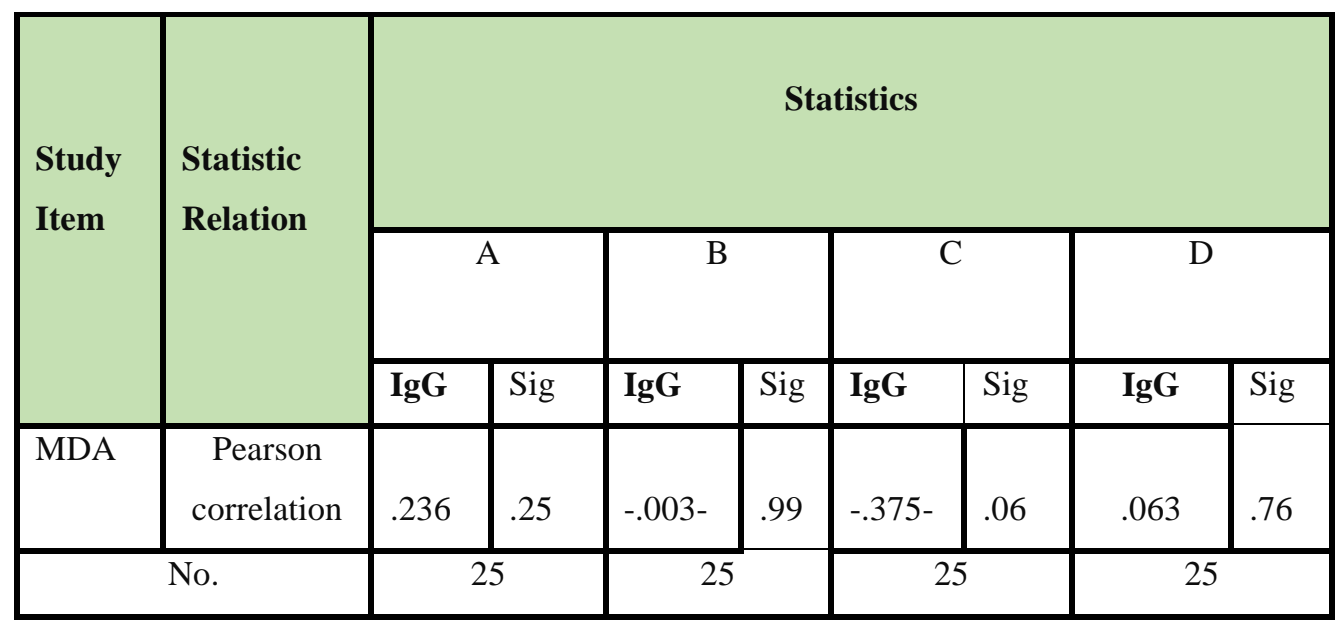

Table 3 shows the correlation between IgG titer and serum ceruloplasmin level in patients and control groups. A positive non-significant Pearson correlation between IgG titer and ceruloplasmin in aborted with CMV and non-aborted with CMV groups. A negative nonsignificant correlation between IgG titer and ceruloplasmin in aborted with non CMV and control groups.

Table 3. Correlation between cytomegalovirus $\operatorname{IgG}$ titer and serum ceruloplasmin in all study groups.

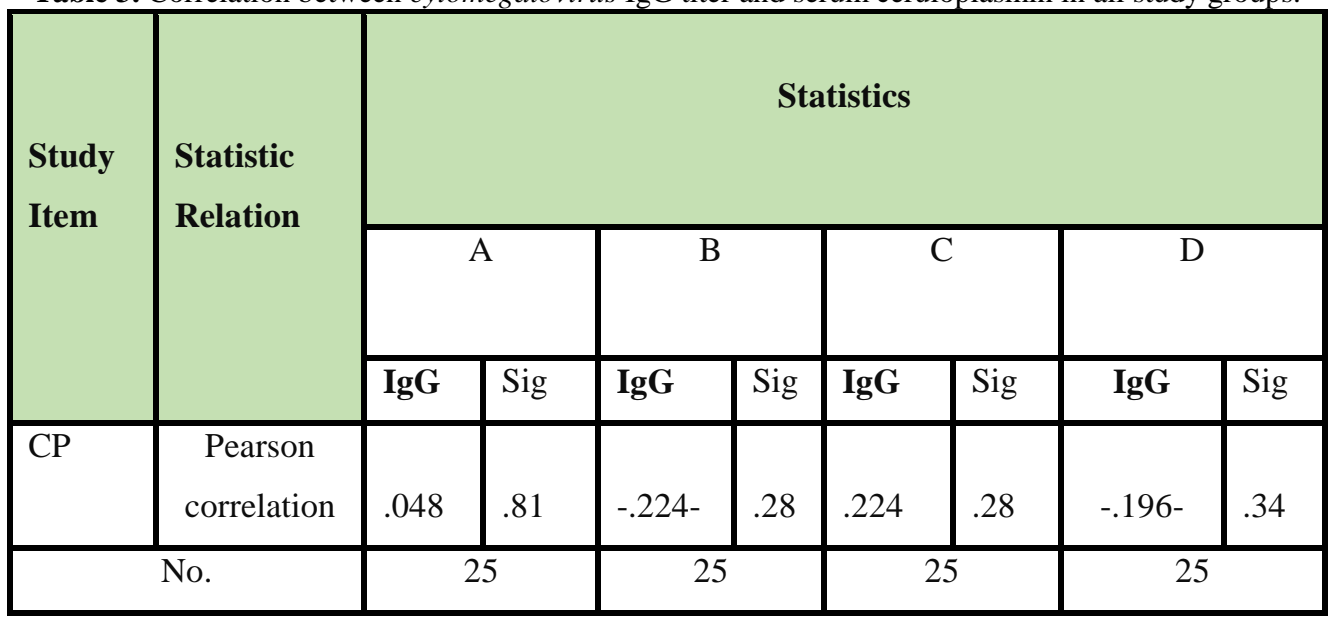

Table 4 shows the correlation between $\operatorname{IgG}$ titer and serum transferrin level in patients and control groups. A negative non-significant Pearson correlation amongst IgG titer and serum transferrin level is observed in aborted with CMV and control groups. A positive significant correlation between CMV IgG titer and transferrin level in aborted group with non CMV and positive non-significant correlation in a non-aborted group with CMV was revealed in the same table.

Table 4. Correlation between cytomegalovirus IgG titer and serum transferrin in all study groups. 


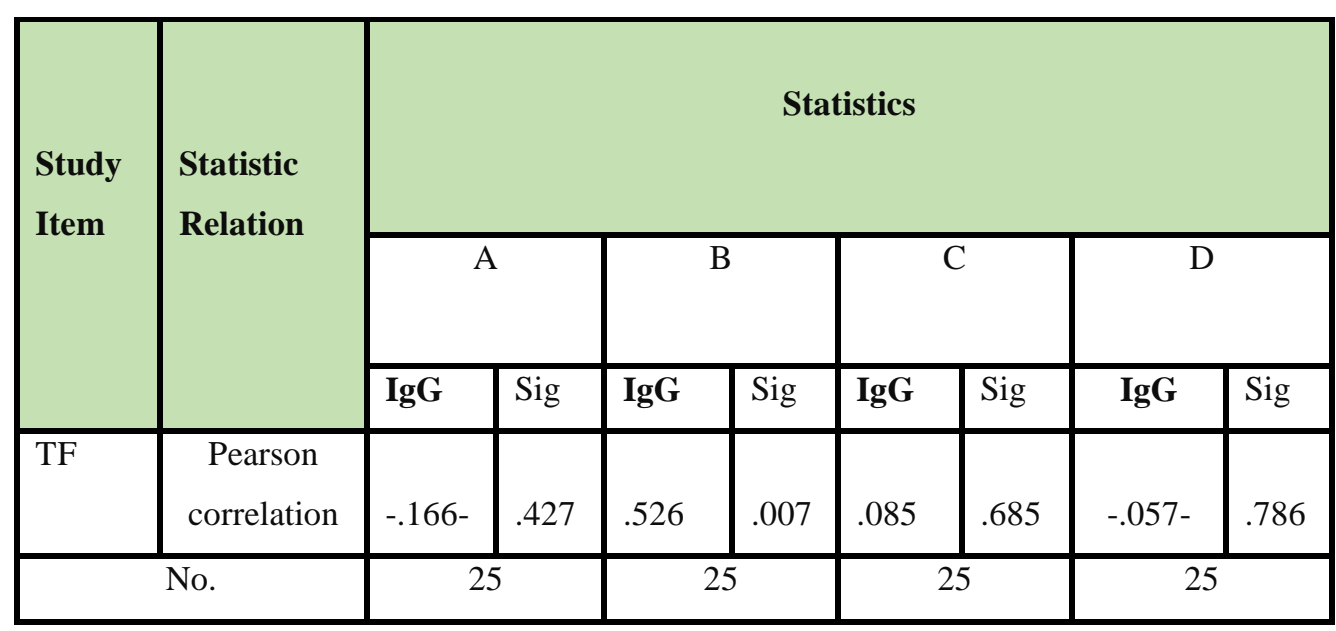

\section{Discussion}

Vitamin D has been shown to promote the immune system and antiviral responses by inducing autophagy and the creation of antimicrobial peptides such as catholicising, and it is thought to play a role in protecting the developing foetus from infections during pregnancy [12]. Many cells in the body, including those in the placenta, have the vitamin D receptor, and many of them can convert 25 -hydroxyvitamin $\mathrm{D}(25(\mathrm{OH}) \mathrm{D})$, the predominant circulating form of vitamin $\mathrm{D}$, to its bioactive form, 1,25-dihydroxy vitamin $\mathrm{D}(1,25(\mathrm{OH}) \mathrm{D} 2)$ [13]. In the presence of particular conditions or stimuli, this enables for local synthesis of 1, $25(\mathrm{OH}) \mathrm{D} 2$ and subsequent vitamin D-dependent antimicrobial immune responses [14].

Lower levels of the bioactive form of vitamin D, calcitriol $(1,25(\mathrm{OH}) \mathrm{D} 2)$, have been linked to an increase in both congenital and peri/postpartum CMV infections in perinatally exposed but HIV-uninfected infants born to non-breastfeeding HIV-positive women [15], which is completely consistent with the current study.

During viral infection, inflammatory cells such as macrophages, neutrophils, and dendritic cells identify, envelop, and phagocytose the virus. The pathogens boost the generation of RS by activating the NADPH oxidase complex and nitric oxide synthase in phagocytic cells [16]. Viruses produce RS in different ways, but they all share a similar pathogenic route that emphasises RS generation and antioxidant depletion [17]. Stehbens, (2004) had reported viral infection to induce server oxidative stress in agreement with my current study [17].

ROS upregulates HCMV lytic replication in fibroblasts via extracellular and intracellular pathways, according to Xiao et al., (2015). Furthermore, antioxidant pre-treatment reduces HCMV replication in vitro and in vivo [18], which explains the positive correlation between IgG titer and MDA serum level in the current study.

The antioxidant is expressed at levels capable of sustaining tolerable amounts of ROS within the cells under non-stressed conditions, allowing redox-sensitive activities to function [19]. Some of the effects of stress response induction can help the viral infection, while others can be harmful. The human cytomegalovirus has a number of mechanisms to deal with the negative features of cellular stress responses while keeping the positive ones [20]. According to Tilton et al. (2011), virally infected cells boost the synthesis of antioxidant enzymes that can swiftly remove ROS and maintain redox equilibrium. The current investigation supported Tilton et al., (2011) findings that CMV infection raises antioxidant levels [21]. 
Transferrin and other antioxidant inhibit viral infection. Kotelnikova et al., (2011) that worked on the effectiveness of antioxidants as CMV infection inhibitors in the cell culture of human embryonic fibroblast. This study found that adding antioxidants to the cells reduces viral protein concentrations in the cells to levels similar to those found in non-infected cell cultures [22]. This study agreed with the current study regarding the aborted group with CMV.

Anti-CMV IgM antibodies level among patients' groups in the current study was too low indicating no acute infection with CMV among aborted women which consider as a limitation for the study.

\section{Conclusion}

The severity of cytomegalovirus infection positively correlated with vitamin D, MDA, and ceruloplasmin and negatively correlated with transferrin as oxidative stress biomarkers.

\section{References}

[1] Baek KH, Lee EJ, Kim YS. Recurrent pregnancy loss: the key potential mechanisms. Trends in molecular medicine. 2007 Jul 1;13(7):310-7.

[2] Zheng D, Li C, Wu T, Tang K. Factors associated with spontaneous abortion: a cross-sectional study of Chinese populations. Reproductive health. 2017 Dec;14(1):1-9.

[3] El Hachem, Hady, Vincent Crepaux, Pascale May-Panloup, Philippe Descamps, Guillaume Legendre, and Pierre-Emmanuel Bouet. "Recurrent pregnancy loss: current perspectives." International journal of women's health 9 (2017): 331.

[4]Landolfo S, Gariglio M, Gribaudo G, Lembo D. The human cytomegalovirus. Pharmacology \& therapeutics. 2003 Jun 1;98(3):269-97.

[5] Nigro G, Mazzocco M, Mattia E, Di Renzo GC, Carta G, Anceschi MM. Role of the infections in recurrent spontaneous abortion. The Journal of Maternal-Fetal \& Neonatal Medicine. 2011 Aug 1;24(8):983-9.

[6]Camini FC, da Silva Caetano CC, Almeida LT, de Brito Magalhaes CL. Implications of oxidative stress on viral pathogenesis. Archives of Virology. 2017 Apr;162(4):907-17.

[7] Tamblyn JA, Hewison M, Wagner CL, Bulmer JN, Kilby MD. Immunological role of vitamin D at the maternal-fetal interface. Journal of Endocrinology. 2015 Mar 1;224(3):R107-21.

[8] Mott KR, Maazi H, Allen SJ, Zandian M, Matundan H, Ghiasi YN, Sharifi BG, Underhill D, Akbari $\mathrm{O}$, Ghiasi H. Batf3 deficiency is not critical for the generation of $\mathrm{CD} 8 \alpha+$ dendritic cells. Immunobiology. 2015 Apr 1;220(4):518-24.

[9] Urrutia RP, Thorp JM. Vitamin D in pregnancy: current concepts. Current opinion in obstetrics \& gynecology. 2012 Mar;24(2):57.

[10] Ota K, Dambaeva S, Han AR, Beaman K, Gilman-Sachs A, Kwak-Kim J. Vitamin D deficiency may be a risk factor for recurrent pregnancy losses by increasing cellular immunity and autoimmunity. Human reproduction. 2014 Feb 1;29(2):208-19. 
[11] Martorell R, Ascencio M, Tacsan L, Alfaro T, Young MF, Addo OY, Dary O, Flores-Ayala R. Effectiveness evaluation of the food fortification program of Costa Rica: impact on anemia prevalence and hemoglobin concentrations in women and children. The American journal of clinical nutrition. 2015 Jan 1;101(1):210-7.

[12] Campbell GR, Spector SA. Vitamin D inhibits human immunodeficiency virus type 1 and Mycobacterium tuberculosis infection in macrophages through the induction of autophagy. PLoS pathogens. 2012 May 10;8(5):e1002689.

[13] Liu N, Kaplan AT, Low J, Nguyen L, Liu GY, Equils O, Hewison M. Vitamin D induces innate antibacterial responses in human trophoblasts via an intracrine pathway. Biology of reproduction. 2009 Mar 1;80(3):398-406.

[14] Walker VP, Zhang X, Rastegar I, Liu PT, Hollis BW, Adams JS, Modlin RL. Cord blood vitamin D status impacts innate immune responses. The Journal of Clinical Endocrinology \& Metabolism. 2011 Jun 1;96(6):1835-43.

[15] Bearden A, Van Winden K, Frederick T, Kono N, Operskalski E, Pandian R, Barton L, Stek A, Kovacs A. Low maternal vitamin D is associated with increased risk of congenital and peri/postnatal transmission of Cytomegalovirus in women with HIV. PloS one. 2020 Feb 13;15(2):e0228900.

[16] Camini FC, da Silva Caetano CC, Almeida LT, de Brito Magalhaes CL. Implications of oxidative stress on viral pathogenesis. Archives of Virology. 2017 Apr;162(4):907-17.

[17] Stehbens WE. Oxidative stress in viral hepatitis and AIDS. Experimental and molecular pathology. 2004 Oct 1;77(2):121-32.

[18] Go YM, Jones DP. Redox control systems in the nucleus: mechanisms and functions. Antioxidants \& redox signaling. 2010 Aug 15;13(4):489-509.

[19] Alwine, J.C., 2008. Modulation of host cell stress responses by human cytomegalovirus. Human cytomegalovirus, pp.263-279.

[20] Tilton C, Clippinger AJ, Maguire T, Alwine JC. Human cytomegalovirus induces multiple means to combat reactive oxygen species. Journal of virology. 2011 Dec 1;85(23):12585-93.

[21] Kotel'nikova RA, Faingol'd II, Poletaeva DA, Mishchenko DV, Romanova VS, Shtol'ko VN, Bogdanov GN, Rybkin AY, Frog ES, Smolina AV, Kushch AA. Antioxidant properties of watersoluble amino acid derivatives of fullerenes and their role in the inhibition of herpes virus infection. Russian Chemical Bulletin. 2011 Jun;60(6):1172-6. 